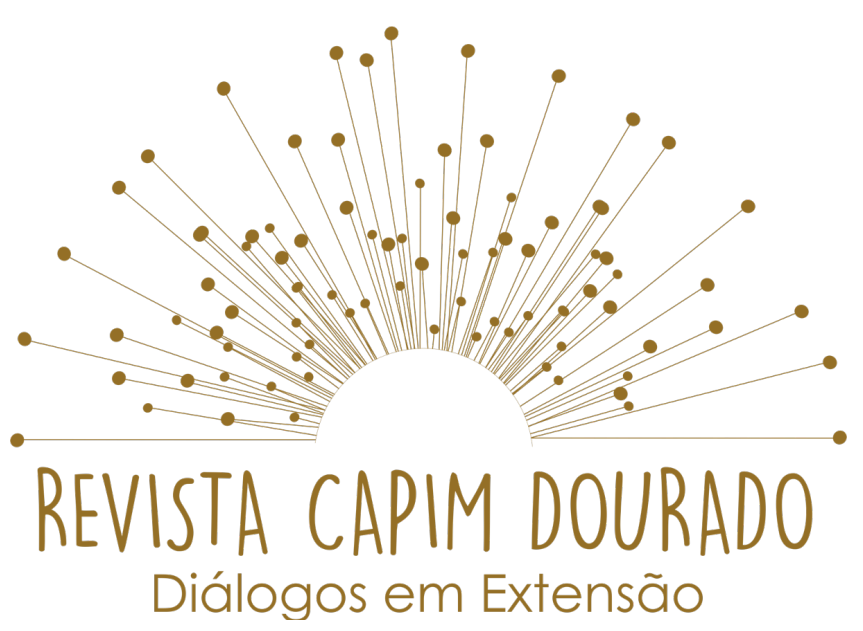

ISSN n² 2595-7341

Vol. 3, n. 2, Maio-Agosto, 2020

DOI: http://dx.doi.org/10.20873/uft.2595-7341.2020v3n2p30

\title{
CONTRIBUIÇÕES DAS INSTITUIÇÕES DE ENSINO SUPERIOR NA EXTENSÃO UNIVERSITÁRIA EM PERÍODO DE ISOLAMENTO SOCIAL DA PANDEMIA COVID-19
}

CONTRIBUTIONS OF HIGHER EDUCATION INSTITUTIONS IN THE UNIVERSITY EXTENSION IN THE PERIOD OF SOCIAL ISOLATION OF PANDEMIA COVID-19

CONTRIBUCIONES DE LAS INSTITUCIONES DE EDUCACIÓN SUPERIOR EN LA EXTENSIÓN UNIVERSITARIA EN EL PERÍODO DE AISLAMIENTO SOCIAL DE LA PANDEMIA COVID-19

\section{Francisco Gilson Rebouças Porto Junior ${ }^{1}$ \\ Meire Lúcia Andrade da Silva² \\ Maria das Graças Pereira Silva ${ }^{3}$ \\ Lêda Lira Costa Barbosa ${ }^{4}$}

\section{RESUMO}

O artigo aborda, questionamentos na área da pandemia da COVID-19, o objetivo geral é: discorrer acerca da pandemia, bem como apresentar algumas instituições que estão desenvolvendo atividades de extensão com foco na pandemia da COVID-19. Tem como questionamento que norteia esta investigação: quais as contribuições da oferta de atividades de extensão em tempos de pandemia da COVID-19? Adota-se perspectiva

1 Doutor em Comunicação e Cultura Contemporâneas. Professor da UFT. E-mail: gilsonportouft@gmail.com.

${ }^{2}$ Docente do curso de Licenciatura em Pedagogia da Universidade Federal do Tocantins (UFT), melucia26@hotmail.com.

${ }^{3}$ Docente do curso de Licenciatura em Pedagogia da Universidade Federal do Tocantins (UFT), Tocantins, gracaprofessor@gmail.com.

${ }^{4}$ Docente de Educação Básica da Rede Estadual de Ensino do Tocantins, josivaniascr@uft.edu.br. 


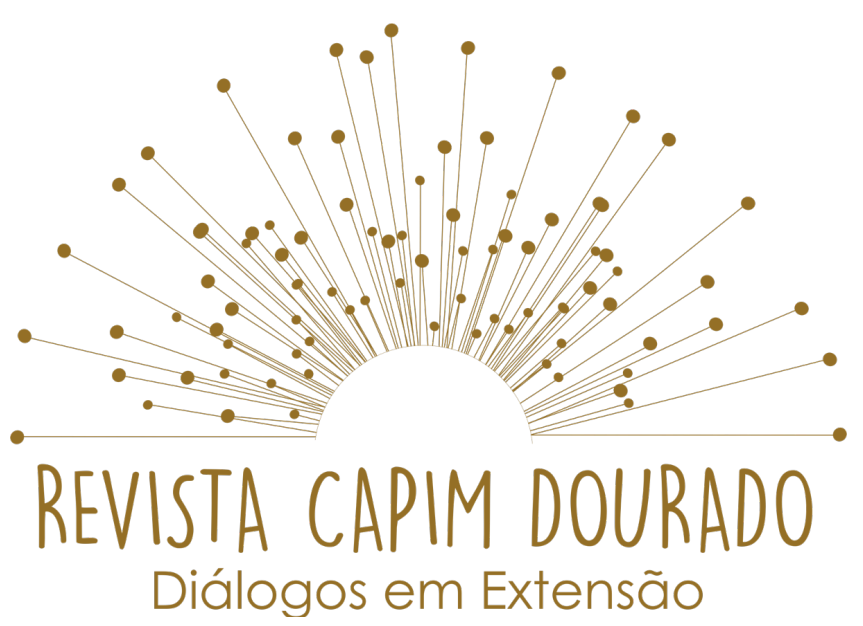

ISSN n² 2595-7341

Vol. 3, n. 2, Maio-Agosto, 2020

DOI: http://dx.doi.org/10.20873/uft.2595-7341.2020v3n2p30

metodológica de pesquisa bibliográfica e documental, as fontes principais de informação são legislações pertinentes, dados e informes publicados em sites e portais. As etapas foram: escolha do tema, levantamento bibliográfico preliminar, análise textual interpretativa e problematização. Encontra-se estruturado em subtópicos que discorrem acerca da temática. Ressalta-se diante da pandemia, algumas atitudes tiveram que ser tomadas seguindo recomendações dos órgãos da saúde, das decisões políticas, administrativas, dos órgãos da gestão pública e de controle, no entanto, grande parte dessas decisões tem gerado mais incertezas do que certezas, sobretudo no meio educacional.

PALAVRAS-CHAVES: Pandemia; contribuições; extensão universitária; COVID-19; educação.

ABSTRACT The article addresses questions in the area of the COVID-19 pandemic, the general objective is: to discuss the pandemic, as well as to present some institutions that are developing extension courses focusing on the COVID-19 pandemic. It has as a question that guides this investigation: what are the contributions of the offer of extension courses in pandemic times of COVID-19? A methodological perspective of bibliographic and documentary research is adopted, the main sources of information are pertinent legislation, data and reports published on websites and portals. The steps were: choice of theme, preliminary bibliographic survey, interpretative textual analysis and problematization. It is structured in subtopics that discuss the theme. It is noteworthy in the face of the pandemic, some actions had to be taken following the recommendations of health agencies, political and administrative decisions, public management and control bodies, however, most of these decisions have generated more uncertainty than certainty, especially in the educational environment.

KEYWORDS: Pandemic; contributions; University Extension; COVID-19; education.

\section{RESUMEN}

El artículo aborda cuestiones en el área de la pandemia COVID-19, el objetivo general es: discutir la pandemia, así como presentar algunas instituciones que están 


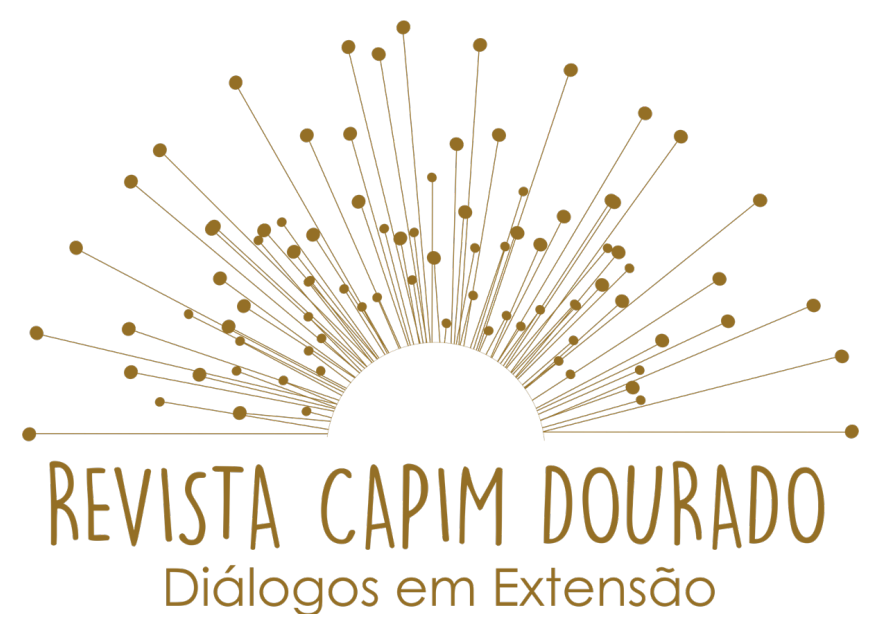

ISSN n² 2595-7341

Vol. 3, n. 2, Maio-Agosto, 2020

DOI: http://dx.doi.org/10.20873/uft.2595-7341.2020v3n2p30

desarrollando actividades de extensión enfocadas en la pandemia COVID-19. Tiene la pregunta que guía esta investigación: ¿cuáles son los aportes de la prestación de actividades de extensión en tiempos de pandemia de COVID-19? Se adopta una perspectiva metodológica de investigación bibliográfica y documental, las principales fuentes de información son la legislación pertinente, datos e informes publicados en sitios web y portales. Los pasos fueron: elección de tema, levantamiento bibliográfico preliminar, análisis textual interpretativo y problematización. Está estructurado en subtemas que tratan el tema. Es de destacar ante la pandemia, algunas actitudes debieron ser tomadas siguiendo recomendaciones de organismos de salud, decisiones políticas y administrativas, órganos de gestión pública y control, sin embargo, la mayoría de estas decisiones han generado más incertidumbre que certeza, especialmente en el entorno educativo.

PALABRAS CLAVE: Pandemia; contribuciones; extensión Universitaria; COVID-19; educación.

Recebido em: 31.03.2020. Aceito em: 19.04.2020. Publicado em: 30.05.2020. 


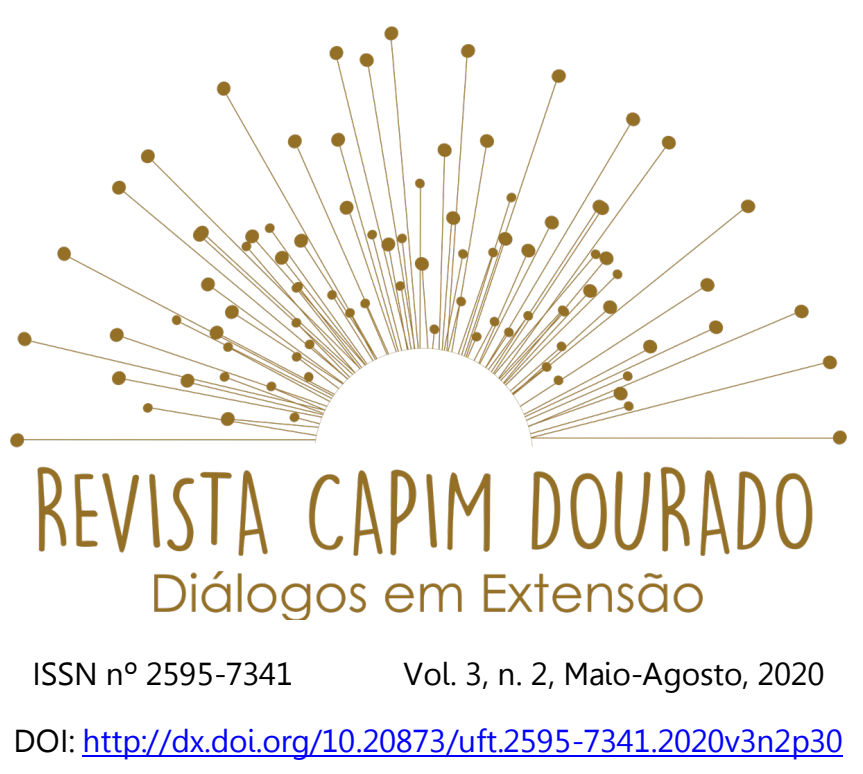

\section{Introdução}

O ano de 2020 será difícil de esquecer. É um ano em que uma das maiores pandemias da história se alastra por quase todos países do mundo. Percebemos então que as fronteiras tão rígidas são imaginárias para a natureza não humana. O vírus não respeita as divisões de países, não pede licença, não solicita "visto" e aparentemente não respeita a divisão de classe, gênero ou raça. Ao mesmo tempo, ele escancara as mazelas do mundo capitalista. (SOARES, 2020).

Este artigo resulta de pesquisa realizada com base bibliográfica e documental, as fontes principais de informação são legislações pertinentes, dados e informes publicados em sites e portais, definição de propostas e orientações sobre as ações relacionadas a atividades de extensão ofertados pelas instituições públicas de ensino superior, com ênfase para enfrentamento da Pandemia ocasionada pela COVID-19 e suas implicações no desenvolvimento das políticas educacionais.

Para o desenvolvimento deste estudo, definimos como pilares centrais: a) os impactos da COVID-19 na educação e um breve contexto histórico; b) a atuação das instituições de ensino superior em tempos de pandemia da covid2019; e c) viabilidade de assegurar momentos de estudos aos profissionais da educação por meio de uma política de formação construída em parceria com instituições de ensino superior públicas presentes no Brasil.

Brasil (2020), destaca que a situação que se apresenta em decorrência da pandemia da COVID-19 não encontra precedentes na história mundial do pósguerra. Segundo a UNESCO, milhões de estudantes estão sem aulas com o 


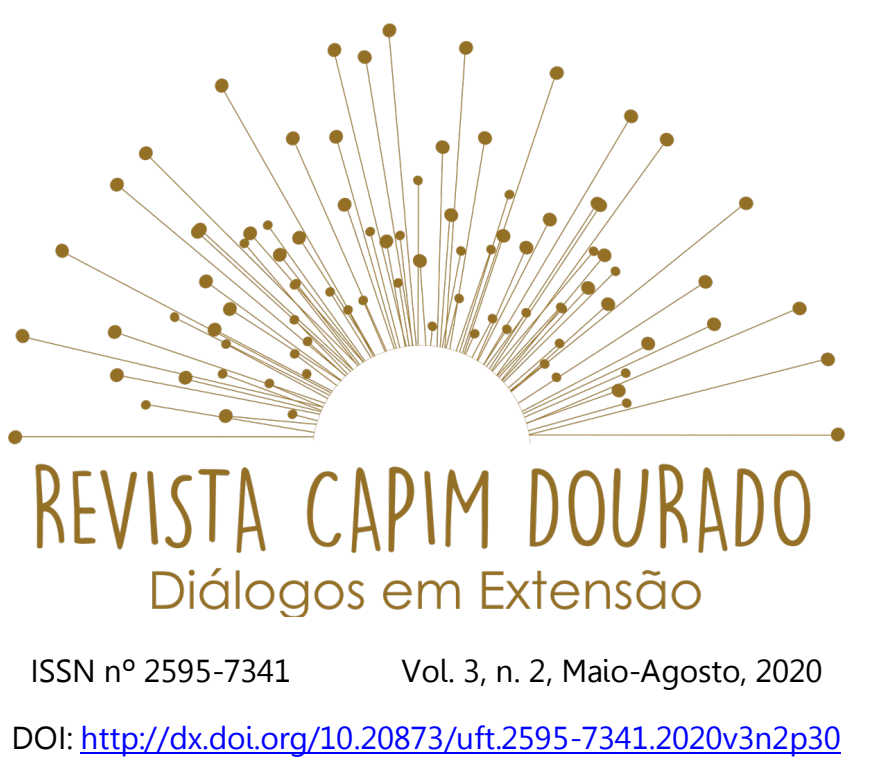

fechamento total ou parcial de escolas e universidades em mais de uma centena de países devido à pandemia do novo Coronavírus. No Brasil, as aulas presenciais estão suspensas em todo o território nacional.

Soares (2020), nos lembra que quando se anuncia a chegada da COVID-19 no Brasil um dos primeiros passos dos governantes para "conter" o vírus é decretar o fechamento das escolas, simbolizando assim que a situação não estava "normal". Os prazos dos decretos seguem sendo ampliados e a pressão pela continuidade dos estudos fez com que se tirasse da gaveta um projeto que há muito tempo fazia parte das aspirações dos governos e empresas privadas de educação: a educação a distância (EeD).

\section{Os impactos da COVID-19 na educação: Breve contexto histórico}

Em 30 de janeiro de 2020, a OMS declarou Emergência de Saúde Pública de Importância Internacional. Em 11 de março de 2020, conforme caracterização da OMS, a doença causada pelo novo Coronavírus, evoluiu a disseminação comunitária da COVID-19 em todos os Continentes, passando a ser caracterizada como pandemia. Em 13 de maio de 2020, mais de 4,2 milhões de pessoas já haviam sido infectadas no mundo, aproximadamente 300 mil mortes (OMS, 2020). Para contê-la, a OMS recomenda três ações básicas: isolamento e tratamento dos casos identificados; testes massivos e distanciamento social.

Oliveira; Sousa (2020), relatam que a COVID-19 é a doença causada pelo novo coronavírus, que foi nomeado de Sars-CoV-2. Esse vírus tem ocasionado problemas políticos, econômicos e sociais de proporções ainda impossíveis de 


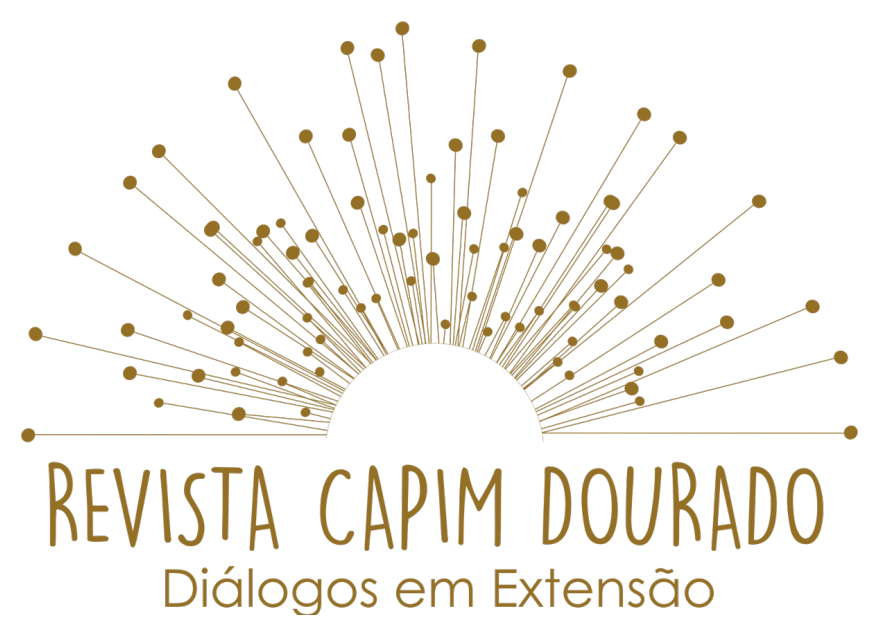

ISSN n² 2595-7341

Vol. 3, n. 2, Maio-Agosto, 2020

DOI: http://dx.doi.org/10.20873/uft.2595-7341.2020v3n2p30

serem efetivamente mensuradas, principalmente pela necessidade da adoção da prática de distanciamento social para reduzir o contágio pelo vírus.

Conforme Oliveira; Souza (2020, p. 16, apud Soares 2020), cabe destacar que,

essa prática de distanciamento social surgiu com a crise espanhola de 1918, sendo considerada eficaz e, portanto, comparando-se ao atual momento, importante medida a ser adotada pela população no combate ao novo coronarívus. Assim, desde a gripe espanhola de 1918, nenhuma outra pandemia influenciou em medidas de distanciamento social. (OLIVEIRA; SOUSA 2020, p. 16, apud SOARES 2020).

Dentre os diversos setores afetados pela COVID-19, o sistema educacional merece destaque, uma vez que, em função dessa pandemia, o direito à educação tem sido abruptamente privado dos estudantes em seus mais diversos níveis de ensino, pois assim como toda a sociedade, a efeito das políticas públicas de saúde adotadas no país, estão em período de distanciamento social, evitando qualquer tipo de aglomeração, como principal medida para reduzir o contágio pelo vírus.

Brasil (2020), destaca que a situação que se apresenta em decorrência da pandemia da COVID-19 não encontra precedentes na história mundial do pósguerra. Segundo a UNESCO, milhões de estudantes estão sem aulas com o fechamento total ou parcial de escolas e universidades em mais de uma centena de países devido à pandemia do novo Coronavírus. No Brasil, as aulas presenciais estão suspensas em todo o território nacional.

Assim, Estados e Municípios vêm editando decretos e outros instrumentos legais e normativos para o enfrentamento da emergência de saúde pública, estando, entre elas, a suspensão das atividades escolares. 


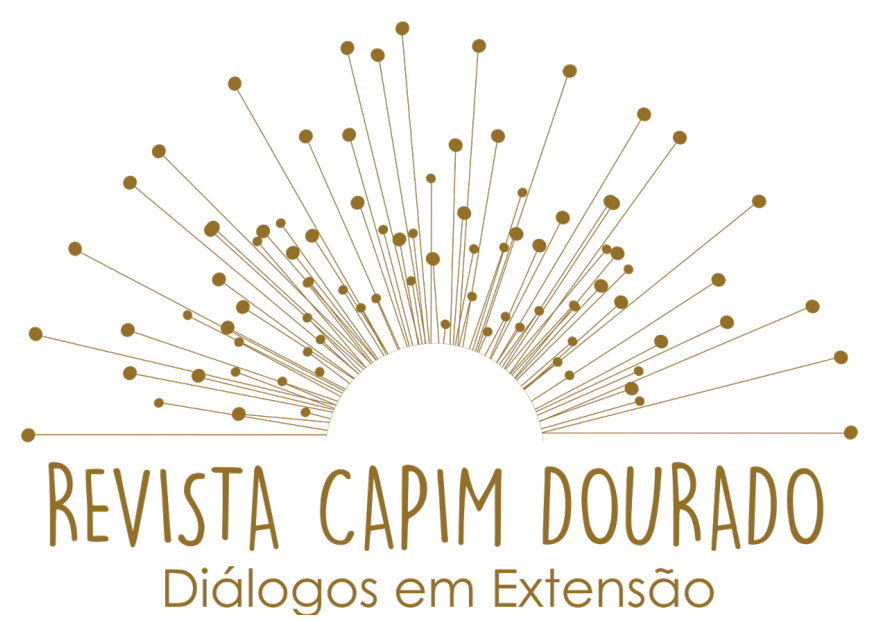

ISSN n² 2595-7341

Vol. 3, n. 2, Maio-Agosto, 2020

DOI: http://dx.doi.org/10.20873/uft.2595-7341.2020v3n2p30

O direito à educação está previsto na Constituição Federal (BRASIL, 1988), - Artigo 205, versa que: "A educação, direito de todos e dever do Estado e da família, será promovida e incentivada com a colaboração da sociedade, visando ao pleno desenvolvimento da pessoa, seu preparo para o exercício da cidadania e sua qualificação para o trabalho". A educação vai além da transmissão do conhecimento, perpassa o preparo para a cidadania.

Entre tanto, não se pode fechar os olhos à crise humanitária que se abateu sob os cidadãos, segundo Santos (2020) com o capitalismo que sujeitou todas as áreas sociais, sobretudo saúde, educação e segurança social, ao modelo de negócio do capital, ao modo gerencial com fins lucrativos para os investidores, principalmente voltado ao ensino EaD, à compra de plataformas virtuais, e cursos oferecidos por muitas instituições no país sem o preparo legal e formativo para docentes. Este modelo põe de lado qualquer lógica de serviço público, e com isso ignora os princípios de cidadania e os direitos humanos. Deixa para o Estado apenas as áreas residuais ou para clientelas pouco solventes (muitas vezes, a maioria da população) as áreas que não geram lucro. Por opção ideológica, seguiu-se:

a demonização dos serviços públicos (o Estado predador, ineficiente ou corrupto); a degradação das políticas sociais ditada pelas políticas de austeridade sob o pretexto da crise financeira do Estado; a privatização dos serviços públicos e o subfinanciamento dos que restaram por não interessarem ao capital. (SANTOS, 2020, p.24).

E chegamos aos nossos dias com os Estados sem capacidade efetiva para responderem eficazmente a essa crise, e consequentemente, as universidades 


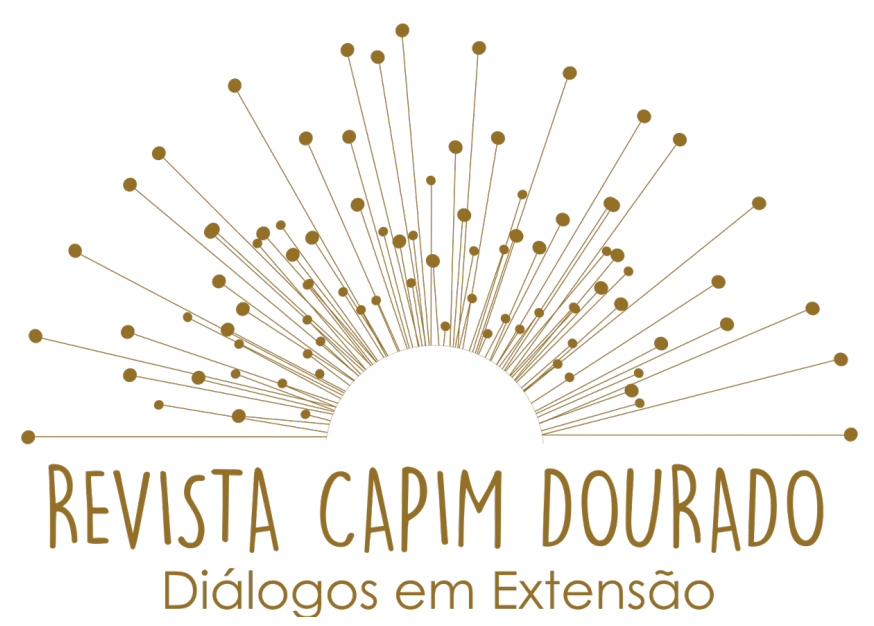

ISSN n² 2595-7341

Vol. 3, n. 2, Maio-Agosto, 2020

DOI: http://dx.doi.org/10.20873/uft.2595-7341.2020v3n2p30

vinculadas que dependem de verbas para se manterem de forma a atender os requisitos legais e à sociedade. $\mathrm{O}$ certo é que temos que apreender ainda as primeiras lições. E Souza (2020) nos ensina com a intensa pedagogia do vírus:

Lição 1. O tempo político e midiático condiciona o modo como a sociedade contemporânea se apercebe dos riscos que corre.

Lição 2. As pandemias não matam tão indiscriminadamente quanto se julga.

Lição 3. Enquanto modelo social, o capitalismo não tem futuro.

Lição 4. A extrema-direita e a direita hiper-neoliberal ficam definitivamente (espera-se) descreditadas.

Lição 5 . O colonialismo e o patriarcado estão vivos e reforçam-se nos momentos de crise aguda.

Lição 6. O regresso do Estado e da comunidade. (SANTOS, 2020, p. 2228)

Desse modo, no atual contexto, o sistema educacional, assim como todas as áreas da sociedade, busca alternativas para se adaptar à nova realidade, uma vez que ainda não é possível definir quando essa crise será estabilizada e, com isso, a vida da população brasileira poderá seguir o seu fluxo, digamos, normal.

Por outro lado, tendo como base os estudos pautados na teoria de (SOARES, 2020), evidencia-se que a solução dos governos, está longe de ser voltada para uma maior solidariedade entre países, ou um maior investimento público no que interessa a população marginalizada (saúde, educação, seguridade social, cultura), é o exato oposto. Aprofundam as desigualdades, salvam os bancos, investem nos aparatos repressivos ao mesmo tempo em que anunciam medidas de austeridades para as áreas sociais.

A autora supramencionada complementa ainda, que. 


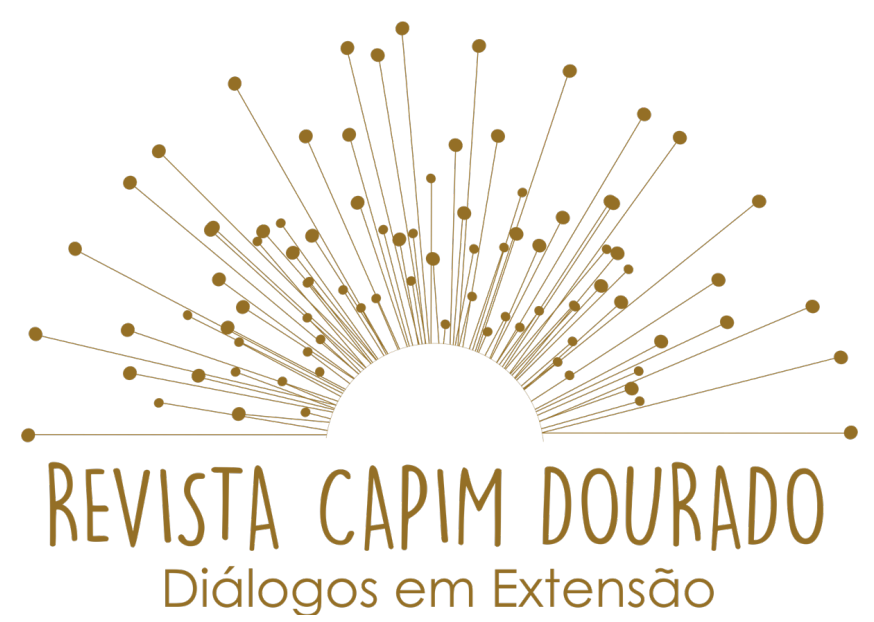

ISSN n² 2595-7341

Vol. 3, n. 2, Maio-Agosto, 2020

DOI: http://dx.doi.org/10.20873/uft.2595-7341.2020v3n2p30

\begin{abstract}
A educação não escapa desse processo de precarização e a pandemia vem apontando para o aprofundamento de duas tendências do projeto neoliberal brasileiro: a ampliação da educação a distância e a militarização das escolas. Tais projetos, apesar de estarem pautados em técnicas distintas, o primeiro na flexibilização do ensino (em uma aparência de desordem) e o segundo na rigidez do ambiente escolar (em uma aparente ordem absoluta), se complementam ao atenderem a dois objetivos comuns: a ultracentralização da educação e o controle sobre os corpos e mentes. (SOARES, 2020, p. 6)
\end{abstract}

Sendo assim, parece-nos claro que esse é um importante momento para repensarmos toda a nossa estrutura educacional e social, ao passo que devemos refletir que para se ter um ensino de qualidade é necessário pensar na questão da formação de professores, em especial desenhada para esse momento de pandemia, dada à complexidade do objeto de discussão quanto à insuficiência do saber pedagógico e ao domínio de saber específico atrelado às competências advindas do saber tecnológico.

\title{
Atuação das instituições de ensino superior em tempos de pandemia da COVID- 2019
}

Muitas instituições de ensino superior desenvolveram agendas de atividades relevantes nesse período de pandemia da COVID-19, optamos por descrever algumas:

a) Campanha Nacional pelo Direito a Educação, esta campanha coordena no Brasil há mais de 17 anos a Semana de Ação Mundial (SAM)5 , sendo esta, a

\footnotetext{
${ }^{5}$ SAM é uma iniciativa realizada simultaneamente em mais de 100 países, desde 2003, com o objetivo de informar e engajar a população em prol do direito à educação (SAM, 2020).
} 


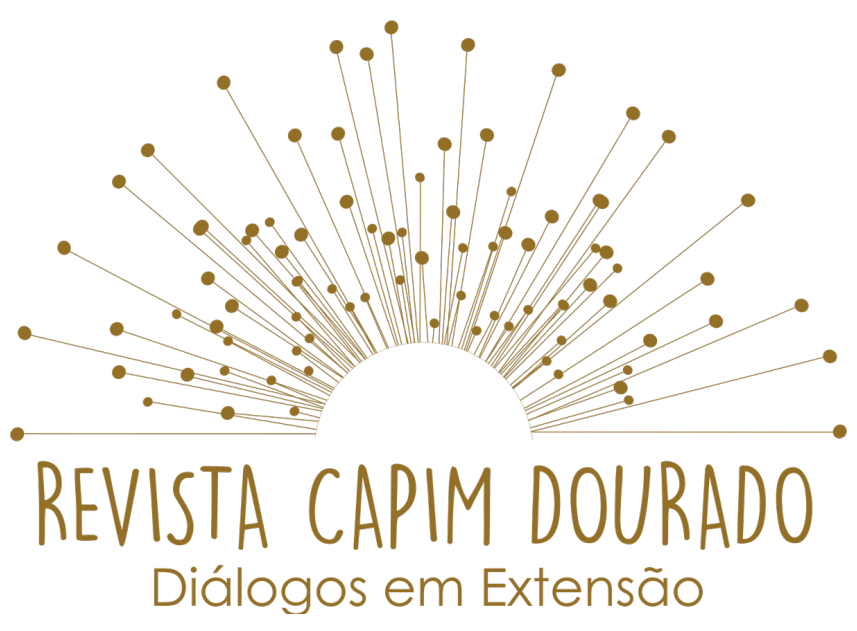

ISSN n² 2595-7341

Vol. 3, n. 2, Maio-Agosto, 2020

DOI: http://dx.doi.org/10.20873/uft.2595-7341.2020v3n2p30

maior atividade de mobilização da sociedade civil pelo direito à educação no mundo.

Em 2020, aconteceram mudanças no formato da SAM por conta das políticas de isolamento para o enfrentamento da pandemia do coronavírus. Em vez das atividades autogestionadas durante a semana, como é de práxis anualmente, proporcionaram webinários (seminários online) sobre o tema da SAM 2020: Educação contra a Barbárie - por escolas democráticas e pela liberdade de ensinar. Conforme apresentado no quadro abaixo:

Quadro 1: Programação da lives SAM (2020).

\begin{tabular}{|l|l|l|}
\hline Data e horário & Temática & Responsáveis \\
\hline $\mathbf{1}^{\text {a live }}$ & "Educação contra a & Mediação: Andressa Pellanda \\
15/06 Segunda & Barbárie: por escolas & Confirmados: Fernando Cássio (UFABC); \\
(17h-19h) & democráticas e pela & Daniel Cara (FE/USP), Carlos Alberto \\
& liberdade de ensinar" & Caetano (UFMT) e Ana Julia Ribeiro. \\
\hline
\end{tabular}

Resumo: nomeou as formas de barbárie e fez um panorama de como a luta contra essa barbárie precisa englobar as comunidades escolares para ampliar as mobilizações.

2a live $\quad$ "Censura e perseguição Mediação: Daniel Cara

16/06 Terça como ameaças à educação Confirmados: Priscylla Silva, Fernando

(17h-19h) de qualidade"

Penna (UFF), Analise da Silva (UFMG) e Rodrigo Ratier (Cásper Líbero)

Resumo: falas potentes e diversas sobre a censura e a atuação nefasta de movimentos ultraconservadores. Desinformação, diálogo e relatos de ações vitoriosas contra as violências da censura aos professores tiveram destaque.

\begin{tabular}{|c|c|c|c|}
\hline & & & \\
\hline $\begin{array}{l}3^{a} \text { live } \\
17 / 06 \text { Quarta } \\
\text { (17h-19h) }\end{array}$ & $\begin{array}{l}\text { "Raça e } \\
\text { construindo } \\
\text { antirracistas' }\end{array}$ & $\begin{array}{r}\text { Educação: } \\
\text { escolas }\end{array}$ & $\begin{array}{l}\text { Confirmadas: Iracema Nascimento } \\
\text { (FE/USP), Deputada Estadual Erica } \\
\text { Malunguinho (PSOL-SP), Suelaine } \\
\text { Carneiro (GELEDÉS Instituto da Mulher } \\
\text { Negra), Macaé Evaristo (GELEDÉS } \\
\text { Instituto da Mulher Negra), Fernanda } \\
\text { Lapa (IDDH) }\end{array}$ \\
\hline
\end{tabular}

Resumo: debate sobre raça e educação, foi uma verdadeira aula sobre a luta histórica antirracista e pela concretização dos direitos humanos na educação. 


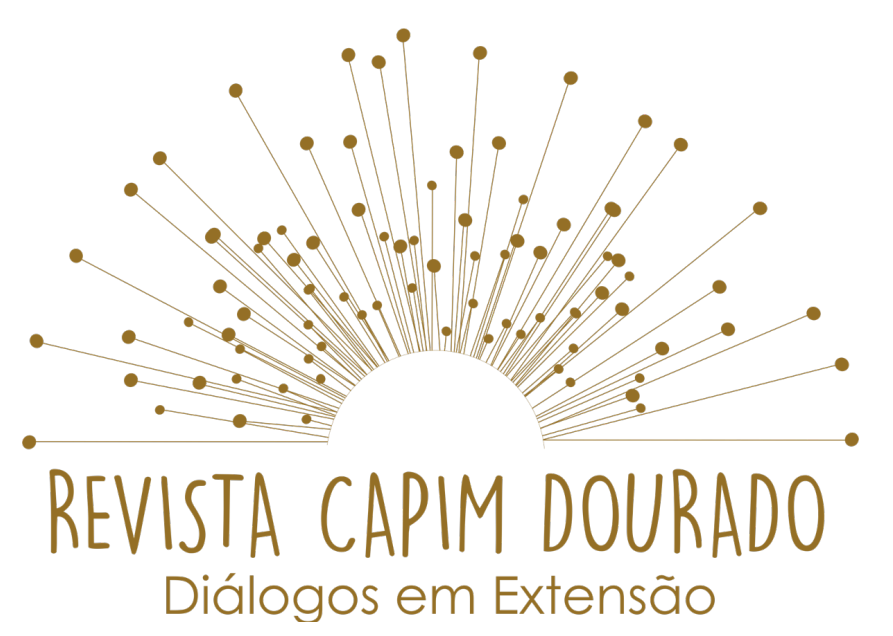

ISSN n² 2595-7341

Vol. 3, n. 2, Maio-Agosto, 2020

DOI: http://dx.doi.org/10.20873/uft.2595-7341.2020v3n2p30

\begin{tabular}{|c|c|c|}
\hline $\begin{array}{l}4^{a} \text { live } \\
18 / 06 \text { Quinta } \\
\text { (17h-19h) }\end{array}$ & $\begin{array}{l}\text { "A ideologia de gênero } \\
\text { existe, mas não é o que } \\
\text { você pensa que é" }\end{array}$ & $\begin{array}{l}\text { Mediação: Andressa Pellanda } \\
\text { Confirmados: Rogério Junqueira (INEP), } \\
\text { Sara York (UERJ), Avanildo Duque } \\
\text { (Comitê PE), Denise Carreira (Ação } \\
\text { Educativa) }\end{array}$ \\
\hline
\end{tabular}

Resumo: ensinou como a discriminação de gênero é manipulada politicamente por grupos reacionários e está sendo bloqueada, com relação à educação, na Justiça.

\begin{tabular}{|c|c|c|}
\hline $\begin{array}{l}5^{a} \text { live } \\
19 / 06 \text { Sexta } \\
\text { (17h-19h) }\end{array}$ & $\begin{array}{lll} & \text { "De onde (não) } & \text { vem o } \\
\text { dinheiro para } & \text { nossas } \\
\text { escolas?" } & & \end{array}$ & $\begin{array}{l}\text { Mediação: Daniel Cara } \\
\text { Confirmados: José Marcelino de Rezende } \\
\text { Pinto (USP), Esther Dweck (UFRJ), } \\
\text { Deputado Federal Bacelar (Podemos-BA), } \\
\text { Élida Graziane (procuradora do MP de } \\
\text { Contas do Estado de São Paulo) }\end{array}$ \\
\hline
\end{tabular}

Resumo: reforçou a certeza da exigência de mais recursos para a educação, seja num \#FundebPraValer, seja defendendo a revogação da EC 95/2016 (Teto de Gastos), de forma a cumprir o que diz a Constituição sobre o direito à educação.

\section{$6^{a}$ live}

20/06 Sábado

(16h-18h)
"Militarização de escolas: Mediação: Daniel Cara

A domesticação como Confirmados: Catarina de Almeida contradição de si mesmo e Santos (FE/UnB), Rudá Ricci, Deputada da realidade"
Federal Sâmia Bomfim (PSOL-SP), Jessica

Moreira (Nós, mulheres da periferia)

Resumo: aprendemos como o projeto bolsonarista está conectado ao projeto de militarização de escolas. E como devemos afirmar mais do que nunca o protagonismo de professoras e professores na educação - seja no Congresso Nacional, seja nos territórios.

\section{$7^{a}$ live}

21/06 Domingo

(16h-18h)
"Privatização 2.0 - As Mediação: Andressa Pellanda novas formas ocultas de Confirmados: Marina Avelar (NORRAG), avanço do setor privado Salomão Ximenes (UFABC), Delphine na educação"
Dorsi (Right to Education Initiative) e Theresa Adrião (Unicamp)

Resumo: como identificar esses processos que, muitas vezes são feitos sem transparência, e conheça opções de regulamentação para a participação do setor privado na educação, como o marco regulatório internacional dos Princípios de Abidjan, o qual a Campanha contribuiu em sua construção.

\begin{tabular}{|c|c|c|}
\hline $\begin{array}{l}8^{a} \text { live } \\
22 / 06 \text { Segunda } \\
\text { (17h-19h) }\end{array}$ & $\begin{array}{lr}\text { "O Plano Nacional de } \\
\text { Educação como norte } \\
\text { contra barbárie na } \\
\text { educação" }\end{array}$ & $\begin{array}{l}\text { Mediação: Catarina de Almeida Santos } \\
\text { Confirmados: Daniel Cara (FE/USP), } \\
\text { Andressa Pellanda (Campanha), Carina } \\
\text { Vitral, deputada federal Jandira Feghali } \\
\text { (PCdoB/RJ) }\end{array}$ \\
\hline
\end{tabular}

Resumo: lançamento do Balanço do Plano Nacional de Educação 2020, elaborado pelo Fernando Rufino, integrante da rede. O monitoramento feito pela Campanha mostra que cerca de $85 \%$ dos dispositivos das metas do Plano não serão cumpridos até o prazo de 2024.

Fonte: elaborado pelos autores, considerando informações do material da Campanha/SAM (2020). 


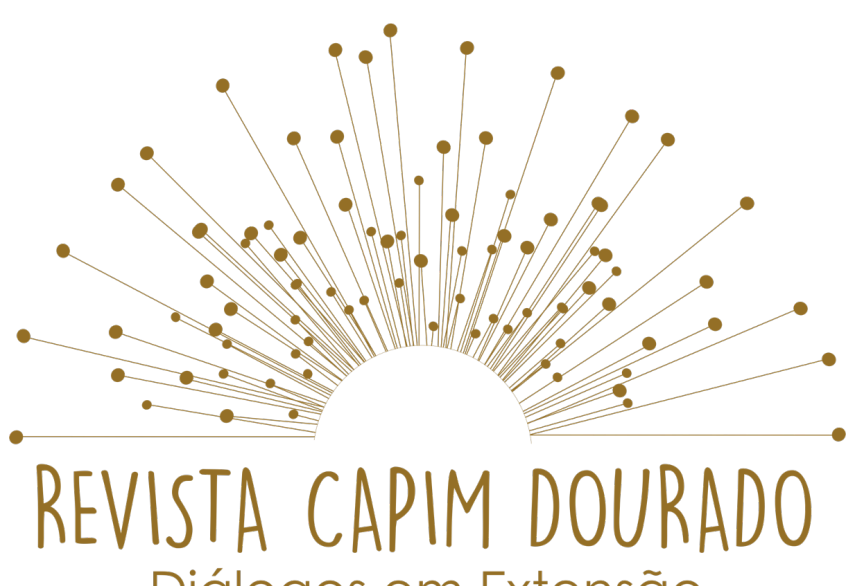

Diálogos em Extensão

ISSN n² 2595-7341

Vol. 3, n. 2, Maio-Agosto, 2020

DOI: http://dx.doi.org/10.20873/uft.2595-7341.2020v3n2p30

Dessa entidade representativa ficou evidenciado que a mesma desenvolve seu papel com muito afinco e responsabilidade, inclusive proporcionando momentos de discussões sobre temas em pauta na educação com especialistas disponíveis gratuitamente, principalmente em tempo de pandemia.

Destacamos como positivo também, o balanço do PNE atualizado nos concretiza como alguns indicadores estão estagnados e outros apresentam retrocessos. "Se o retrato é de descaso com a educação, precisamos saber exatamente a dimensão do problema para solucioná-lo" (SAM, 2020).

O PNE é uma promessa de caminho para a educação e no momento ele é visto como um lugar para nos apoiarmos em "relação às resistências e para virar esse jogo contra o retrocesso, no sentido de retomar uma agenda que avance em termos de acesso, qualidade e permanência na educação". (SAM, 2020).

A SAM proporcionou debates robustos sobre vários assuntos relacionados ao direito à educação e à luta contra a barbárie educacional, bem como, a construção da gestão democrática e do $\mathrm{PNE}$, de sua importância como norte para a educação brasileira, apesar do flagrante descumprimento da lei "precisamos defender o PNE para continuar a lutar por uma educação de qualidade para todas e todos".

Para Tavares e Sousa (2016) buscar a democratização da gestão da educação e da escola pública implica construir disposição, nas pessoas, em aceitar a ideia de que dialogando podem, juntas, construir alternativas mais sólidas para os problemas comuns a todos. Isto se traduz no reconhecimento de 


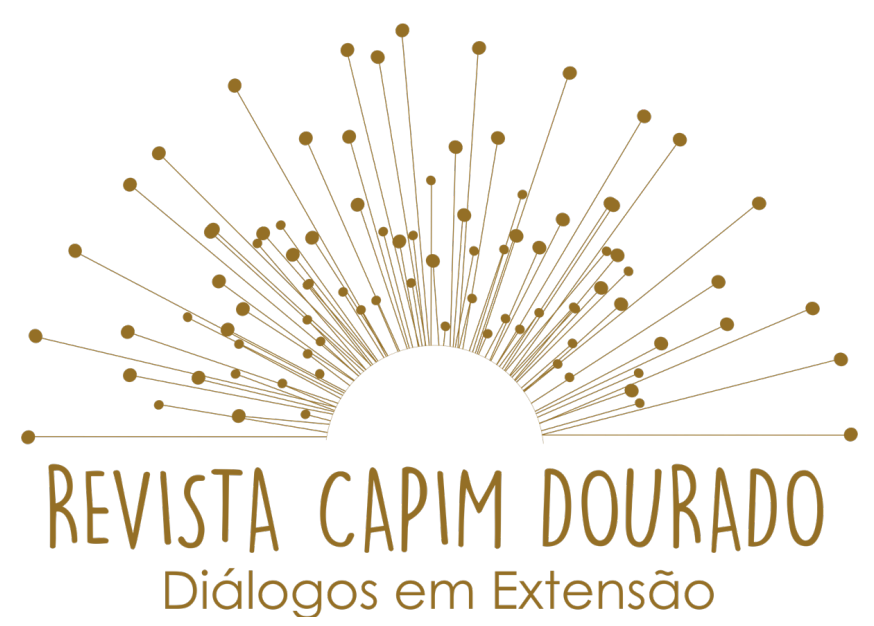

ISSN n² 2595-7341

Vol. 3, n. 2, Maio-Agosto, 2020

DOI: http://dx.doi.org/10.20873/uft.2595-7341.2020v3n2p30

que o que é público advém da compreensão de que existe uma esfera coletiva na vida humana, de interface e convívio entre as pessoas (CHAUÍ, 1997), a qual externa, cotidianamente, aqueles problemas.

b) Instituto Federal de Educação, Ciência e Tecnologia do Tocantins (IFTO). A atuação e contribuição do IFTO foi via OFÍCIO CIRCULAR No 7/2020/REI/IFTO do dia 29 de maio de 2020 de autoria do Senhor Antônio da Luz Júnior - Reitor do Instituto Federal do Tocantins, expedido aos Prefeitos e Secretários Municipais de Educação. Cujo o assunto é oferta de curso de Formação Continuada.

Informamos que o Instituto Federal do Tocantins (IFTO) ofertará o curso de Formação Continuada em Mídias Digitais na Educação Básica, que tem como objetivo a capacitação de servidores das redes municipais de Educação em Tecnologias Digitais, contribuindo para que esses profissionais estejam aptos a planejar e executar atividades de ensino dentro do atual modelo midiático aos discentes da Educação Básica.

Caso haja interesse na oferta desse curso para os professores de seu município, solicitamos que nos enviem a confirmação até 4 de junho e nos informem o e-mail da Secretaria Municipal de Educação para posterior envio do link das inscrições e repasse das demais informações. (IFTO, OFICIO Nº 07, p. 1, 2020).

O quadro a seguir, apresenta o detalhamento do curso ofertado pelo Instituto Federal de Educação, Ciência e Tecnologia do Tocantins (IFTO).

Quadro 2: Detalhamentos do curso (2020).

Temática:

Formação Continuada em Mídias Digitais na Educação Básica

Objetivo geral: 


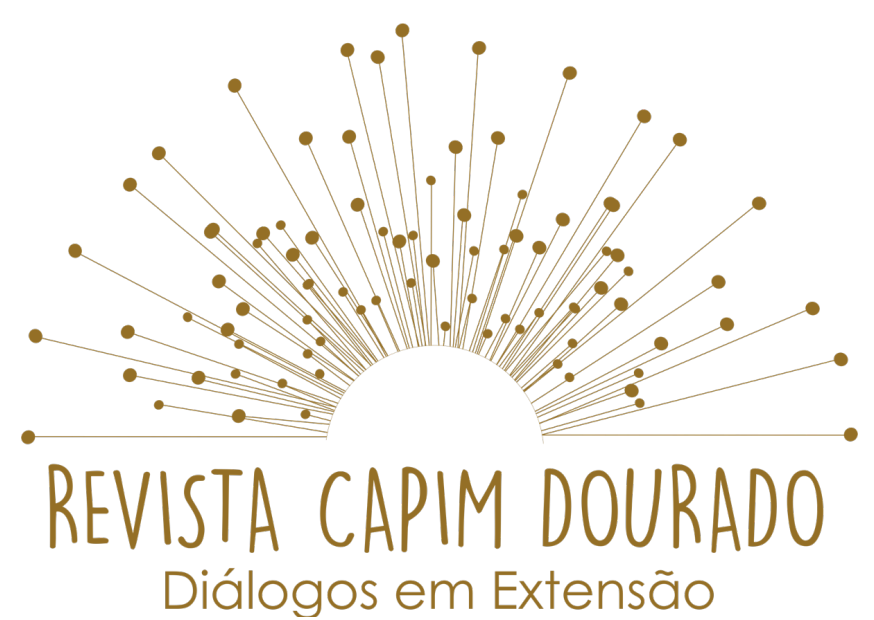

ISSN n०2595-7341

Vol. 3, n. 2, Maio-Agosto, 2020

DOI: http://dx.doi.org/10.20873/uft.2595-7341.2020v3n2p30

-Oportunizar profissionais, de qualquer área do conhecimento para atuarem como mídias digitais no processo de ensino e aprendizagem e no desenvolvimento das habilidades básicas associadas à função no qual desempenha em sua vida profissional ou acadêmica, tais como: familiaridade com as ferramentas tecnológicas, habilidades de motivação e de acompanhamento das atividades à distância.

\section{Objetivos Específicos:}

-Apresentar a evolução, fundamentos e características das mídias digitais;

-Conhecer as teorias e as abordagens filosóficos-pedagógicas e a importância para aprendizagem;

-Apresentar e discutir sobre as principais metodologias aplicadas ao ensino remoto;

-Entender os papéis de cada sujeito dentro do seu nível ou modalidade de ensino;

-Compreender como se processa a avaliação no ensino remoto.

\section{Metodologia do Curso:}

-O Curso será mediado pelos professores e Tutoria, ou seja, durante todo o período do curso o cursista terá na sala de aula a "presença" do Tutor Orientador.

-Esse profissional irá orientá-los quanto à dinâmica do curso, nas realizações das proposições de atividades, contribuir para construção de novos saberes e proporcionar ao cursista, as condições necessárias para aprendizagem autônoma.

\section{Carga horária do curso:}

-O curso, com carga horária de 40 horas.

-Início em 8 de junho de 2020, será gratuito e ofertado na modalidade a distância.

\section{Número de turmas e vagas:}

10 turmas, cada uma com 1.000 (mil) vagas $=10.000,00$ (dez mil) vagas

\section{A sala está organizada em 6 tópicos:}

- MÓDULO I cultural digital em desenvolvimento com a comunidade escolar (16h);

- MÓDULO II metodologias ativas na educação à distância (12h);

- MÓDULO III ferramentas síncronas e assíncronas na educação básica (12h);

-Avaliação da temática e do docente e do curso. 


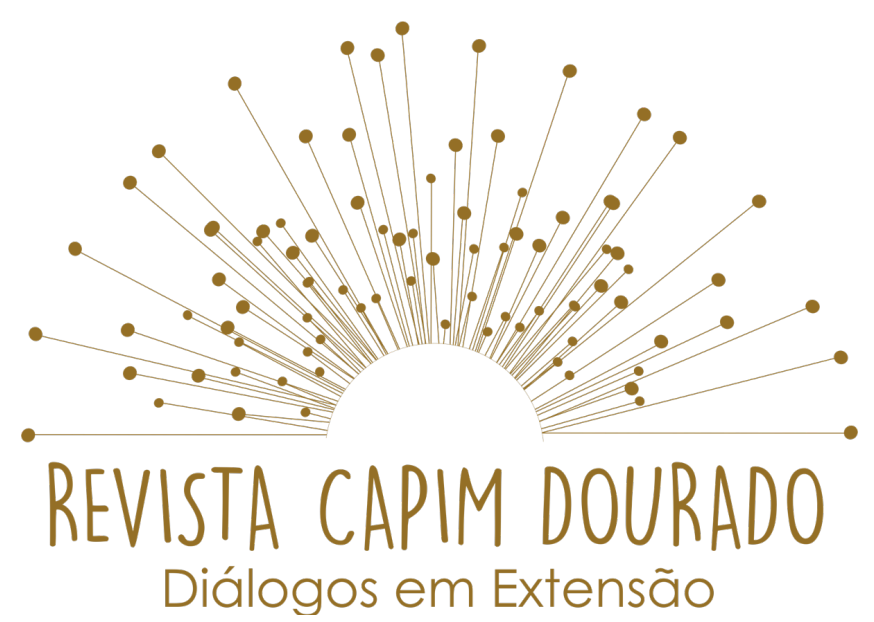

ISSN n² 2595-7341

Vol. 3, n. 2, Maio-Agosto, 2020

DOI: http://dx.doi.org/10.20873/uft.2595-7341.2020v3n2p30

-Emissão do certificado.

Fonte: elaborado pelos autores, considerando Oficio nº 07/ IFTO, (2020).

Sobre essa inciativa colaborativa relatamos como positiva e sensata, pois, o momento da pandemia exigiu e exige dos professores adoção do uso da Tecnologias digitais de informação e comunicação (TIDCs).

A evolução tecnológica não se restringe apenas aos novos usos de determinados equipamentos e produtos. Ela altera comportamentos. A ampliação e a banalização do uso de determinada tecnologia impõem-se à cultura existente e transformam não apenas o comportamento individual, mas o de todo o grupo social. [...] $\mathrm{O}$ homem transita culturalmente mediado pelas tecnologias que lhe são contemporâneas. (KENSKI, 2008, p. 21).

c) Universidade Federal de Goiás - Faculdade de Educação: Núcleo de Estudos e Pesquisas em Psicologia, Educação e Cultura (NEPPEC). Com o com o objetivo de discutir o futuro do mundo no pós-pandemia da COVID-19 e o papel das Instituições de Ensino Superior.

Quadro 03: Programação do curso Diálogos em tempo de cólera e Simpósio Ciência, Arte e Educação em tempos de pandemia (2020)

Temática: Diálogos em tempos de cólera

Curso livre virtual de 01 de junho a 17 de agosto segundas-feiras - das $19 \mathrm{~h}$ às $21 \mathrm{~h}$

Dia 01/06 - O desafio do conhecimento - com Anita C. Azevedo Resende

Dia 08/06 - Conhecimento e barbárie: conhecer e rebarbarizar

com Cynthia Maria Jorge Viana

Dia 15/06 - Estado moderno e a relação entre o público e o privado

com Maria Augusta Peixoto Mundim

Dia 22/06 - Neoliberalismo e neoconservadorismo

com Marília Gouvêa de Miranda 


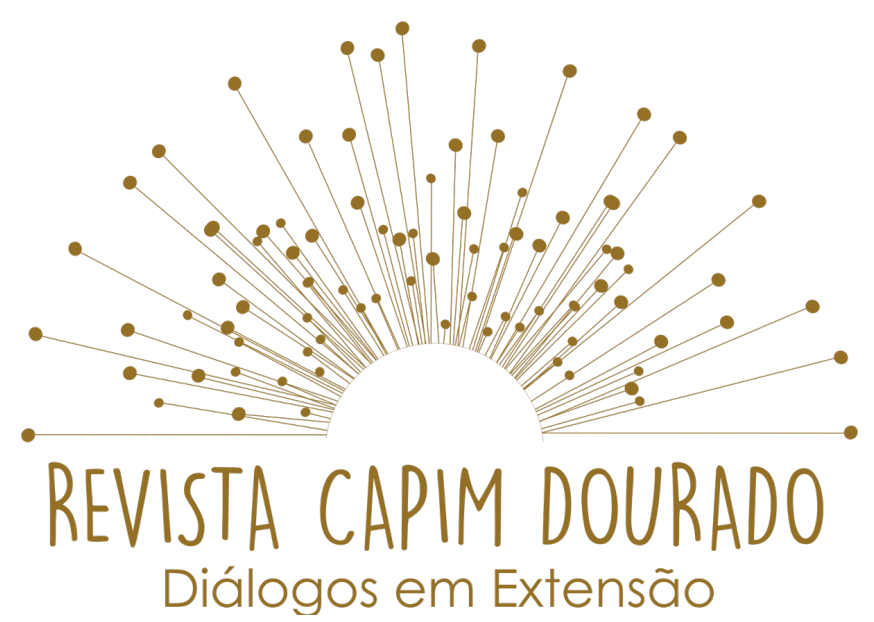

ISSN n² 2595-7341

Vol. 3, n. 2, Maio-Agosto, 2020

DOI: http://dx.doi.org/10.20873/uft.2595-7341.2020v3n2p30

Dia 29/06 - Luta de classes: outra vez à luta!
com Lênin Tomazett Garcia
Dia 06/07 - Escola e a reprodução da desigualdade
com Gina Glaydes Guimarães Faria
Dia 13/07 - Sujeito e cultura: Freud em tempos sombrios
com Renata Leite Soares
Dia 20/07 - Sofrimento psíquico e temporalidade
com Leilyane Oliveira Araújo Masson
Dia 27/07 -Agressividade: pensando com a psicanálise
com Lara Mendes Cesar
Dia 03/08 - Barbárie: elementos para pensar a resistência
com Juliana de Castro Chaves
Dia 10/08 - Passado no presente: velhice em tempos de pandemia
com Mona Bittar
Dia 17/08 -A indústria cultural e a propaganda fascista
com André Barcellos Carlos de Souza
Simpósio Ciência, Arte e Educação em tempos de pandemia
08 de junho 2020 às 19:30 a 16 de junho 2020 às 21:30
O evento abordará cinco painéis:
1- Pandemias: passado, presente e futuro;
2- Instituições de Ensino: presente e futuro;
3- Ciência, tecnologia e desenvolvimento: o papel do Estado;
4- Arte, cultura e humanidade(s): reflexões na pandemia;
5- Informação e política na pandemia: narrativas em conflito.

Fonte: elaborado pelos autores, considerando a programação online (2020).

No âmbito da UFG, a extensão universitária é compreendida como processo educativo, cultural e científico que articulado ao ensino e à pesquisa, de forma indissociável, viabiliza a relação transformadora entre a Universidade e a Sociedade.

A extensão tem pautado suas ações por três grandes objetivos: integrar ensino e pesquisa na busca de alternativas, visando apresentar soluções para problemas e aspirações da comunidade; organizar, apoiar e acompanhar ações que visem à interação da universidade com a sociedade, gerando benefícios 


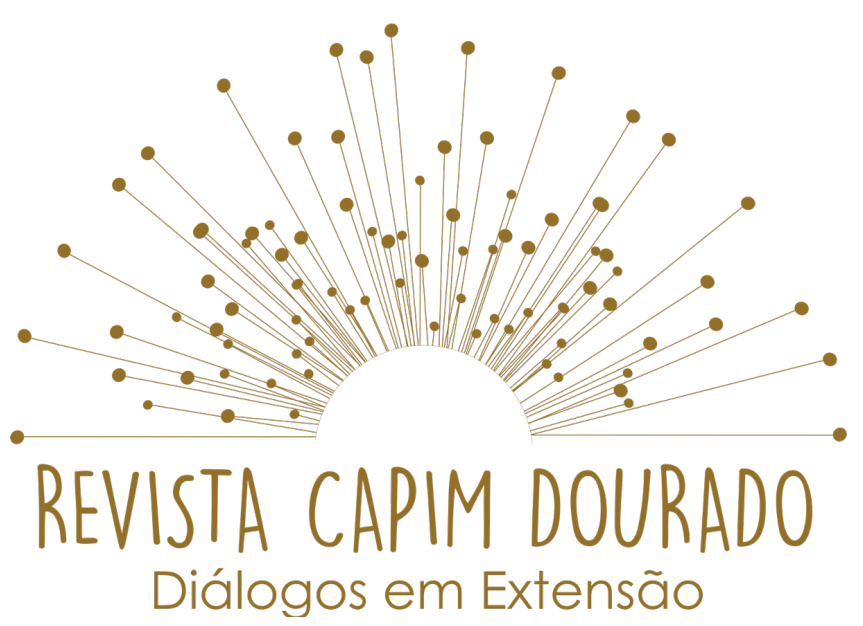

ISSN n² 2595-7341

Vol. 3, n. 2, Maio-Agosto, 2020

DOI: http://dx.doi.org/10.20873/uft.2595-7341.2020v3n2p30

para ambas e incentivar a produção cultural da comunidade acadêmica e comunidades circunvizinhas.

\section{d) Pontifícia Universidade Católica de Minas Gerais}

O curso de Pedagogia da PUC Minas sensível à situação em que todos estão imersos devido ao COVID-19, decide por inovar na forma de mobilizar conhecimentos produzidos no campo da Educação. O XIII Simpósio de Pedagogia da PUC Minas: Pedagogia e Pedagog@s em Tempos de Pandemia foi modificado para fortalecer laços acadêmicos e propor discussões que remontam à situação que vivemos, assim como apresenta a essencialidade e os desafios do trabalho do pedagog@ em tempos de pandemia. Assim, foi um evento online.

Quadro 04: programação do evento (2020).

\section{0/05-10 Dia}

$14 \mathrm{~h}$ - Abertura do Evento

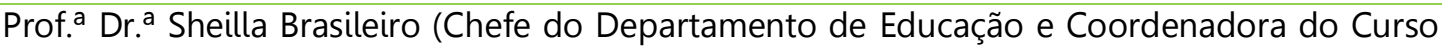
de Pedagogia da PUC Minas)

Repentes

Prof. ${ }^{a}$ Dr. ${ }^{a}$ Lorene dos Santos (PUC Minas)

Conferência de Abertura: Pedagogia e Pedagog@s em Tempos de Pandemia

Prof. Dr. Luciano Mendes de Faria Filho (Pedagogo, Doutor em Educação, Coordenador do Projeto Pensar a Educação/Pensar o Brasil - UFMG)

Atividade Cultural: Flashmob - Pedagog@s em Harmonia (Estudantes do curso de Pedagogia da PUC Minas)

Mesa Redonda: Usos das tecnologias digitais na escola em tempos de pandemia

Prof. Dr. Vítor Gonçalves (IPB - Portugal); Bruno Ferrari (Nave à Vela); Gabriel Matos (Escola Integra); Vitor Fiuza (PUC Minas)

Fala Professor! Pedagogia e Pedagog@s em tempos de pandemia: reflexões dos docentes da Pedagogia PUC Minas

21/05 - $2^{\circ}$ Dia

$14 \mathrm{~h}$ - Abertura do Evento

Meditação para combater a fadiga do cérebro e viver sua excelência

Dharamgun Kaur (PUC Minas)

Mesa Redonda: Pedagogia da pandemia: o que estamos aprendendo com tudo isso? 


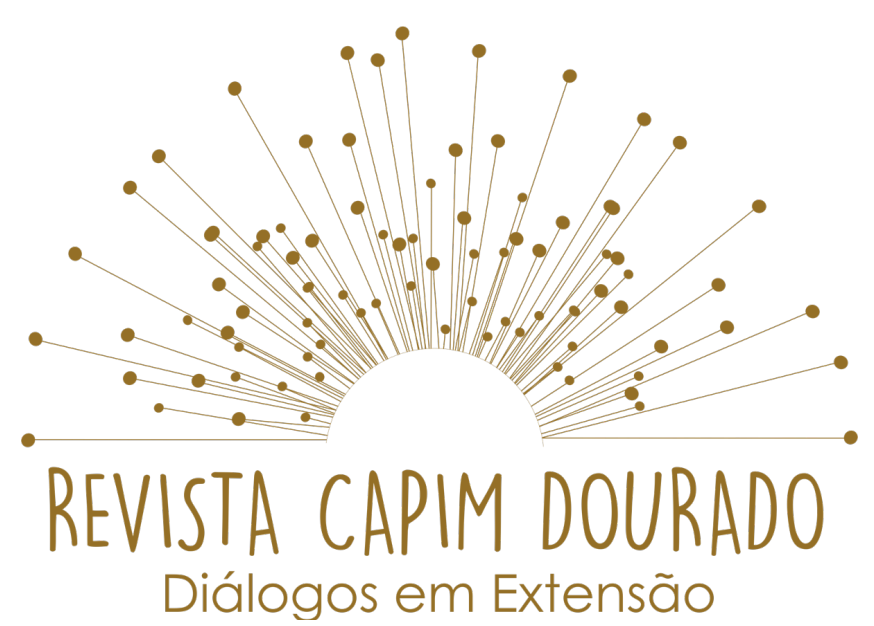

ISSN n² 2595-7341

Vol. 3, n. 2, Maio-Agosto, 2020

DOI: http://dx.doi.org/10.20873/uft.2595-7341.2020v3n2p30

\begin{abstract}
Prof. ${ }^{a}$ Dr. ${ }^{\text {a }}$ Sheilla Brasileiro (PUC Minas); Pedagoga Jaqueline Dantas (Pedagoga do Hospital João XXIII) ; Prof. ${ }^{a}$ Dr. ${ }^{a}$ Augusta Mendonça (Professora da Rede Municipal de Educação de Belo Horizonte) ; Pedagoga Marita Gastin (Coordenadora Pedagógica de Escola da Rede Particular de Ensino); Pedagoga Keila Magalhães (Coordenadora do Centro de Educação Infantil do Hospital Albert Einsten - SP)

Atividade Cultural: O carinho em tempos de COVID-19

Prof. Dr. Edmundo de Novaes Gomes (PUC Minas)

Conferência de Encerramento: A pandemia e a legislação: um aprofundamento da desigualdade escolar

Prof. Dr. Carlos Roberto Jamil Cury (PUC Minas)

Atividade Cultural: Em Mim

Laura Alaane (Estudante do Curso de Pedagogia da PUC Minas)

Coreografia: Aline Batista

Homenagem dos Formandos

Encerramento do Evento

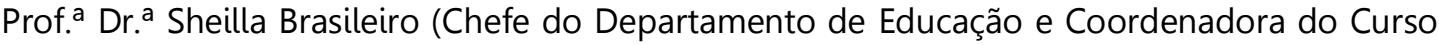
de Pedagogia da PUC Minas).
\end{abstract}

Fonte: Elaborado pelas autoras (2020)

\title{
e) Universidade Federal do Tocantins (UFT)
}

A UFT inicia nesta semana as reflexões junto à comunidade acadêmica para elaboração do Projeto Pedagógico Institucional (PPI), documento que norteia o ensino, pesquisa e extensão na instituição. Abaixo estão as respectivas datas das reuniões em cada campus, que serão realizadas de forma online. 0 objetivo é discutir o cenário formativo da UFT, problemas contemporâneos, pesquisas e práticas desenvolvidas referentes ao ensino, à pesquisa e à extensão, priorizando mitigar os índices de retenção e evasão, com vistas à elaboração de políticas institucionais. O resultado dos trabalhos subsidiará a elaboração do Projeto Pedagógico Institucional - PPI, para potencializar a qualidade da 


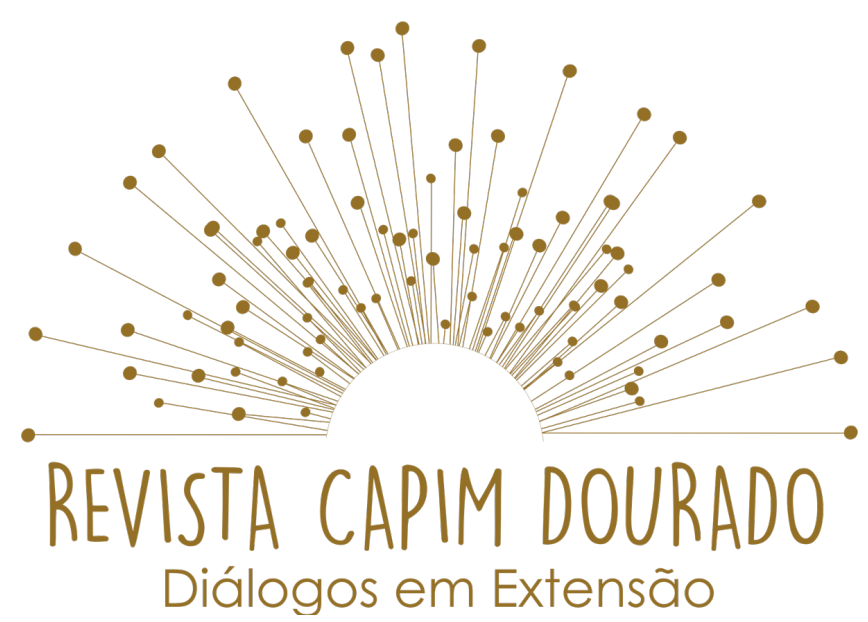

ISSN n² 2595-7341

Vol. 3, n. 2, Maio-Agosto, 2020

DOI: http://dx.doi.org/10.20873/uft.2595-7341.2020v3n2p30

formação na graduação e na pós-graduação da UFT, evidenciando a identidade institucional. A Semana de reuniões online para discussão ${ }^{6}$ :

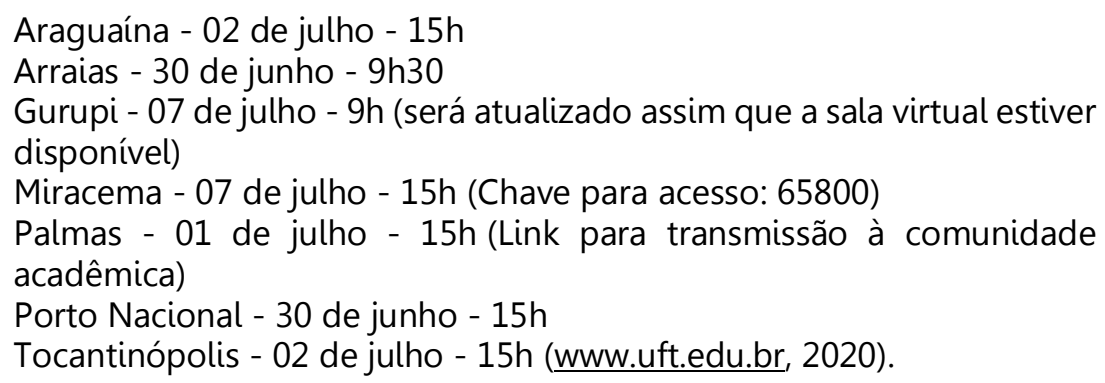

Sobre os grupos de trabalho:

GT 1: Metodologia de Ensino - Inovação pedagógica: desafios conceituais e metodológicos para o ensino e à aprendizagem; relação teoria e prática; respeito ao outro e às culturas, tecnologias educacionais.

Presidente: Ana Carmem de S. Santana.

GT 2: Avaliação de Cursos- Avaliação interna e externa de cursos: indicadores e critérios; avaliação por área de conhecimento.

Presidente: Clarete de Itoz

GT 3: Estrutura e Conteúdo Curricular - Matriz formativa; flexibilização curricular; prérequisitos; formas de oferta de disciplinas; objetos de conhecimento - competências e habilidades (dcns); creditação da extensão.

Presidente: Eduardo Cezari

GT 4: Avaliação de Programas de Formação Acadêmica e Assistência Estudantil - Apoio aos alunos-ingressantes, programas e impactos na formação, avaliação da aprendizagem, tecnologias educacionais.

Presidente: Fernando S. Barros

\footnotetext{
${ }^{6}$ Tocantinópolis - 02 de julho - 15h (https://ww2.uft.edu.br/index.php/ultimas-noticias/27557uft-inicia-semana-de-reunioes-online-para-discussao-de-novas-praticas-pedagogicas.
} 


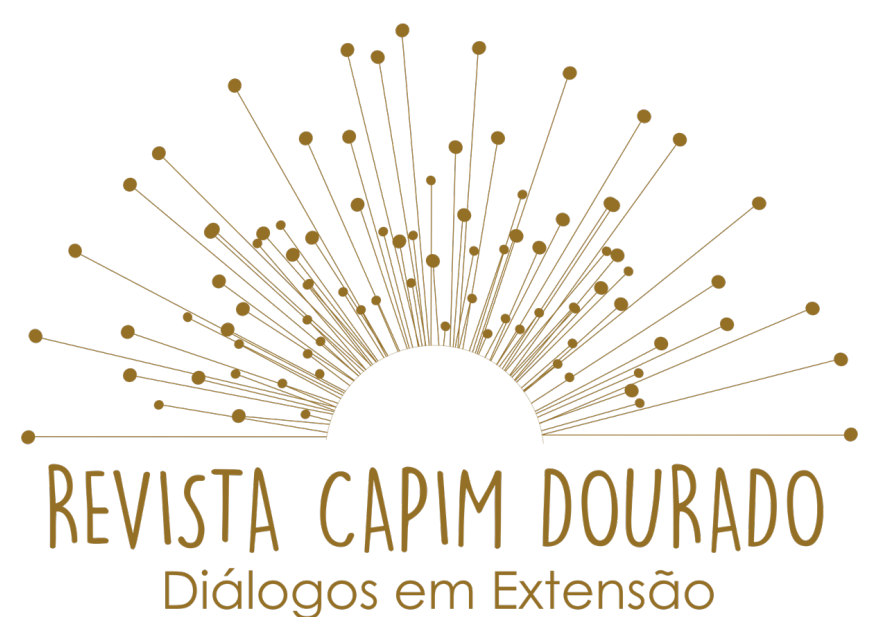

ISSN n² 2595-7341

Vol. 3, n. 2, Maio-Agosto, 2020

DOI: http://dx.doi.org/10.20873/uft.2595-7341.2020v3n2p30

GT 5: Ingresso na UFT - objetos de conhecimento; conexão educação básica e educação superior; ideal universitário e realidade da formação básica.

Presidente: Ladislau do Nascimento

GT 6: Egresso UFT - Formação e Mundo do Trabalho; perfil do egresso; formação profissional.

Presidente: Eduardo Simões

GT 7: Internacionalização - qualidade do ensino, pesquisa e extensão; desafios conceituais e metodológicos; responsabilidade social, pedagógica, econômica, cultural e política; conexão com a educação básica; objetivos; respeito ao outro e às culturas.

Presidente: Thelma Lage. Fonte: <https://ww2.uft.edu.br/index.php/ultimasnoticias/27557-uft-inicia-semana-de-reunioes-online-para-discussao-de-novaspraticas-pedagogicas >, 2020.

De acordo o artigo $43^{\circ}$ da LDB, a educação superior tem por finalidade:

[...] VII - promover a extensão, aberta à participação da população, visando à difusão das conquistas e benefícios resultantes da criação cultural e da pesquisa científica e tecnológica geradas na instituição;

VIII - atuar em favor da universalização e do aprimoramento da educação básica, mediante a formação e a capacitação de profissionais, a realização de pesquisas pedagógicas e o desenvolvimento de atividades de extensão que aproximem os dois níveis escolares. (BRASIL, 1996).

Assim, Rodrigues; Prata; Batalha (2013) consideram que a extensão universitária possui papel importante no que diz respeito às contribuições que pode trazer frente à sociedade. É preciso, por parte da Universidade, apresentar concepção do que a extensão tem em relação à comunidade em geral. Colocar em prática aquilo que foi aprendido em sala de aula e desenvolvê-lo fora dela. A partir do momento em que há esse contato entre o aprendiz e a sociedade beneficiada por ele, acontece por parte dos dois lados, benefícios. "Aquele que 


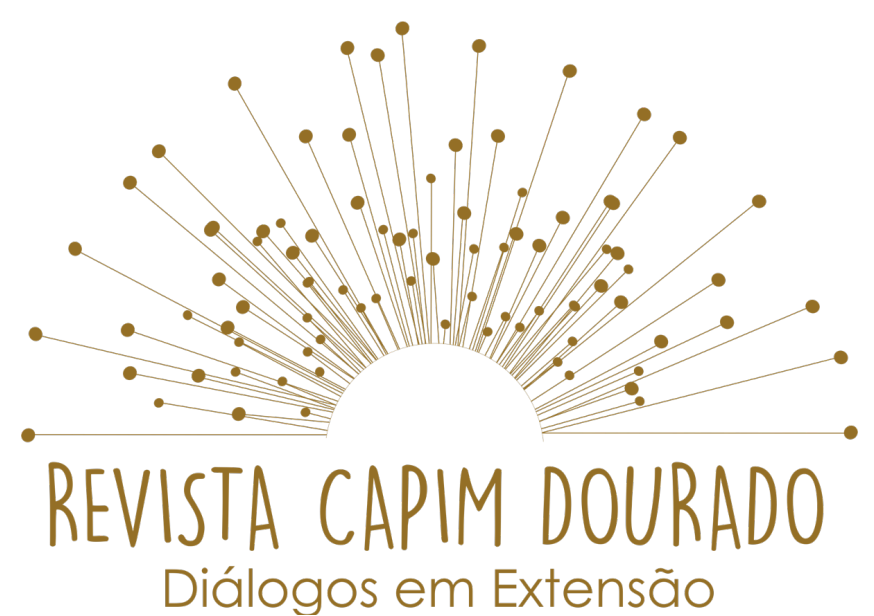

ISSN n² 2595-7341

Vol. 3, n. 2, Maio-Agosto, 2020

DOI: http://dx.doi.org/10.20873/uft.2595-7341.2020v3n2p30

está na condição do aprender acaba aprendendo muito mais quando há esse contato, pois torna-se muito mais gratificante praticar a teoria recebida dentro da sala de aula. Esse é o conceito básico de extensão". (RODRIGUES; PRATA; BATALHA, 2013, p. 143).

Para tanto, a relação da universidade com a comunidade se fortalece pela extensão universitária, ao proporcionar diálogo entre as partes e a possibilidade de desenvolver ações sócio-educativas que priorizam a superação das condições de desigualdade e exclusão ainda existentes.

Diante da oferta de atividade relacionadas nessa categoria das instituições CAMPANHA, IFTO, UFG PUC e UFT, constata-se brilhante atuação e disseminação de saberes e práticas coletivas. Essas instituições não ficaram inertes no período da pandemia. A medida em que socializa e disponibiliza seu conhecimento, tem a oportunidade de exercer e efetivar o compromisso com a melhoria da qualidade de vida dos cidadãos. (ROCHA, 2007 apud SILVA, 2011, p.2). O entendimento a respeito da relação entre extensão e sociedade, é uma visão fundamental que possibilita a qualidade da assistência prestada para as pessoas.

Contudo, Freire (1979) define a natureza humana, eminentemente como de reflexão e relação. Só a pessoa humana é capaz de objetivar a realidade e refletir a respeito dela, cabe à universidade, enquanto órgão formador, estimular a construção de espaços e ambientes capazes de propiciar momentos de reflexão dessa realidade. 


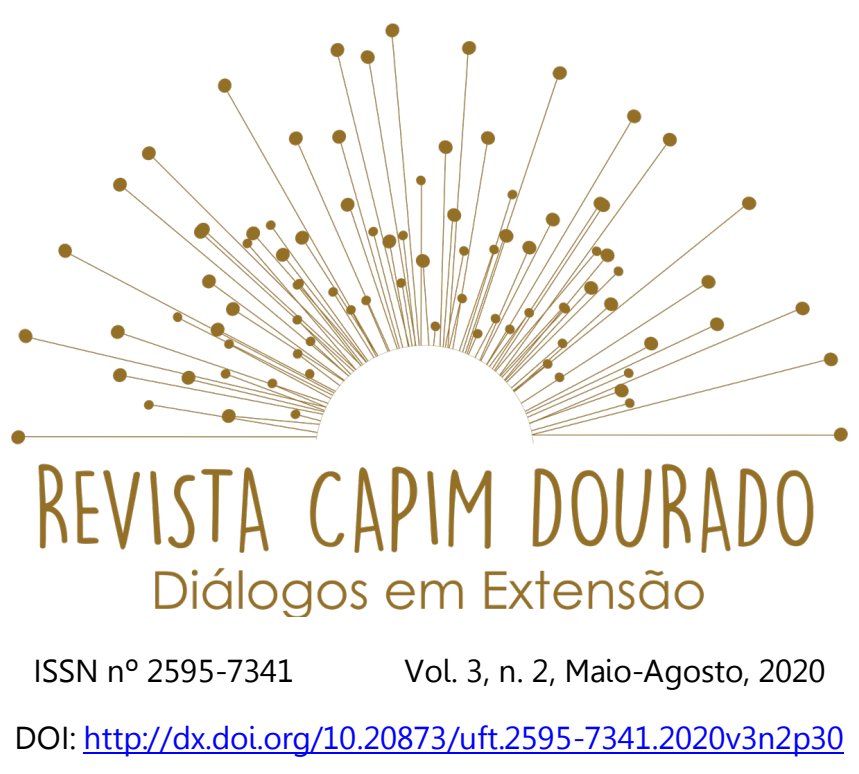

Tecendo aprendizagem com tecnologias de groupware para a educação: aprendizagem colaborativa semipresencial na universidade

A crescente digitalização das informações na sociedade contemporânea tem produzido consequências irreversíveis no modo de produção, construção e disseminação do conhecimento. Uma vez que o novo estilo digital engendra, obrigatoriamente, não apenas o uso de novos equipamentos para a produção e apreensão do conhecimento, mas também novos comportamentos de aprendizagem, novas racionalidades, novos estímulos perceptivos. (Queiroz, 2003, p. 37 apud KENSKI, 1998, p. 61).

Nesse contexto de pandemia, os caminhos que se vislumbram para a educação contemporânea, apontam para formas de aprendizagem mais solidárias, e menos autoritárias. A abordagem pedagógica aprendizagem colaborativa vem ganhando espaço, e se constitui numa modalidade educacional apropriada, para atividades coletivas em redes de produção de conhecimento, em especial, com a internet. Ambientes digitais para o desenvolvimento de atividades cooperativas, são em geral denominados de groupware. Existem diversas soluções destinadas a estas atividades no formato de sistemas de computação colaborativa, que utilizam redes internet ou intranet para proporcionar a interação dos participantes, através de variados recursos. (QUEIROZ, 2003, p. 40)

A aprendizagem colaborativa favorece a complementação de conhecimentos, habilidades, capacidades e a resolução de problemas complexos, a partir da geração criativa de soluções e maior motivação para 


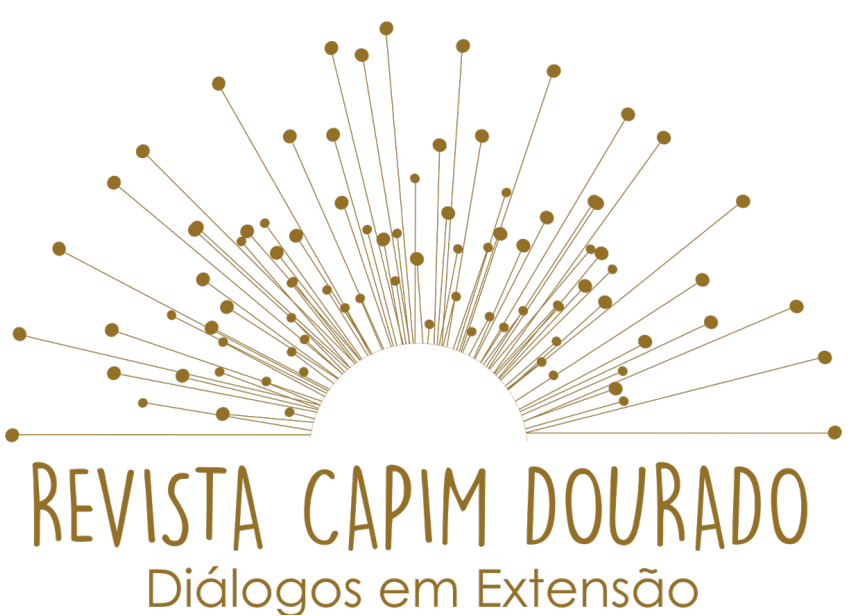

ISSN n² 2595-7341

Vol. 3, n. 2, Maio-Agosto, 2020

DOI: http://dx.doi.org/10.20873/uft.2595-7341.2020v3n2p30

estudantes e professores, gerando intercambiamento dinâmico e interativo de informações e conhecimentos, redimensionando percepções geográficas e temporais, através do efeito de aceleramento das interações e relações sociais por meio de variados dispositivos de interface gráfica e recursos multimídia presentes na web. Logo, o conhecimento não é a informação disponibilizada pelo professor de modo convencional, mas o conteúdo apreendido pelo estudante através de sua própria experiência e das discussões com outros colegas do grupo e com o professor.

Tais contribuições precisam ser ampliadas, construídas e conhecidas para que se possa redimensionar a práxis pedagógica obsoleta, ainda presente na maioria das nossas universidades. Ao contrário do que se possa pensar, o imediato pós-quarentena não será um período propício a discutir alternativas, a menos que a normalidade da vida a que as pessoas quiserem regressar não seja de todo possível.

\section{Notas conclusivas}

Mediante o desafio apresentado a pandemia causada pela COVID-19 trouxe grandes transformações ao processo educativo. As mudanças que foram exigidas neste novo cenário são os primeiros passos de uma grande transformação que está por vir: o uso efetivo das tecnologias digitais na educação; a cocriação; o compartilhamento; a participação; e a criação colaborativa de conhecimentos e recursos educacionais pelos professores. 


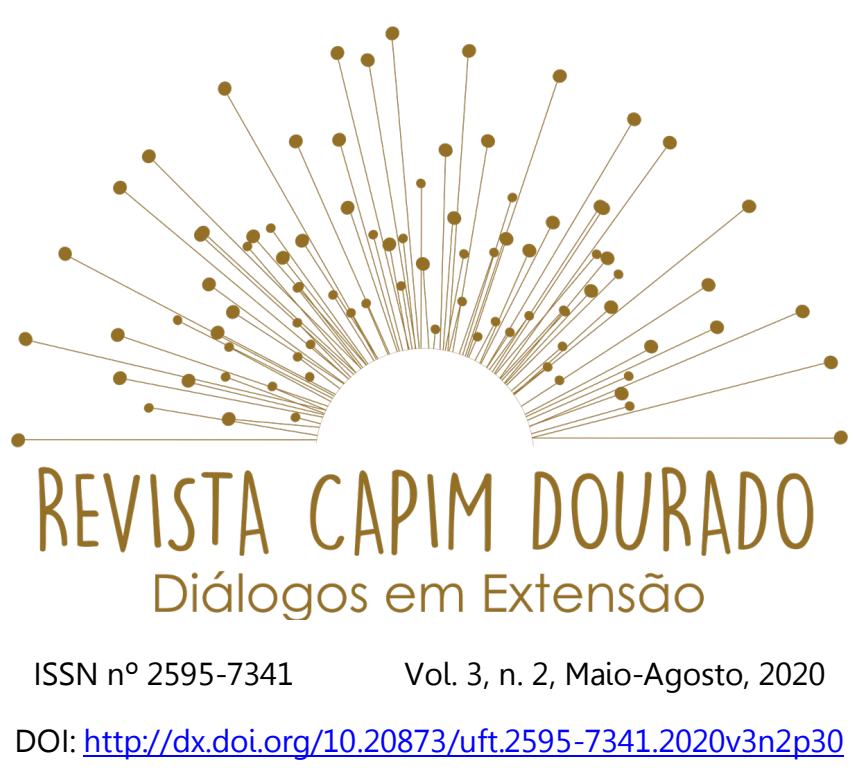

Dessa forma, a alternativa vivenciada pelos sistemas de ensino, imediatamente após a suspensão de aulas, num esforço conjunto entre professores, gestores e família, é a utilização de recursos de tecnologia e informação (comunidades no Facebook, WhatsApp, You Tube etc.) para o envio de atividades escolares aos educandos no formato de vídeos gravados no celular, indicação de canais educativos, lives nas redes sociais, dentre outras, como também a disponibilização de recursos já existentes (materiais impressos/xerocópias, entrega de livros didáticos), especialmente àqueles que não dispõem de computadores, tablets ou celulares e nem mesmo acesso à internet.

Não há neste momento um modelo perfeito que atenda às necessidades de cada escola, rede de ensino e universidade, tamanha a diversidade dos sistemas de ensino, mas permanecem invioláveis direitos e garantias assegurados na Constituição Federal no tocante à Educação, assim como os deveres de cada um desses atores do processo educacional.

Os governantes têm tomado decisões que não são fáceis como: a necessidade de paralisar uma Cidade, um Estado ou País, diante disso, devemos lembrar que nenhuma esfera social estava preparada para esta pandemia e de certa forma, estamos tendo que "aprender a aprender" a lidar com esta situação, mas, tendo como princípio primordial, a preservação da vida.

Diante da pandemia, algumas atitudes tiveram que ser tomadas seguindo recomendações dos órgãos da saúde, das decisões políticas, administrativas, dos órgãos da gestão pública e de controle, no entanto, grande 


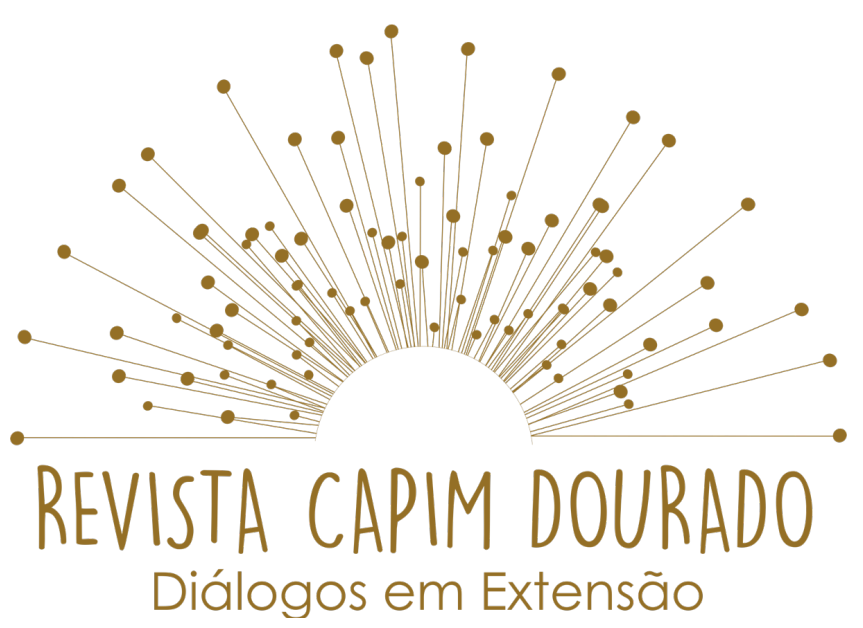

ISSN n² 2595-7341

Vol. 3, n. 2, Maio-Agosto, 2020

DOI: http://dx.doi.org/10.20873/uft.2595-7341.2020v3n2p30

parte dessas decisões tem gerado mais incertezas do que certezas, sobretudo no meio educacional.

A oferta da educação é um serviço essencial para a formação do cidadão ou melhor, "é um direito garantido na Constituição Federal e princípio fundamental para a cidadania", no entanto, devido a ação do COVID-19, tornouse impossível garantir a segurança dos estudantes na realização de aulas presenciais, nesse momento.

\section{REFERÊNCIAS}

BRASIL, Diário Oficial da União. Órgão: Ministério da Educação/Gabinete do Ministro. PORTARIA No 343, DE 17 DE MARÇO DE 2020. Dispóe sobre a substituição das aulas presenciais por aulas em meios digitais enquanto durar a situação de pandemia do Novo Coronavírus - COVID-19. Publicado em: 18/03/2020 | Edição: 53 | Seção: 1 | Página: 39.

BRASIL. Constituição da República Federativa do Brasil. Brasília: Planalto, 1988. Disponível em: <www.planalto.gov.br>. Acesso em: 09/04/2020.

BRASIL. Instituto Federal de Educação, Ciência e Tecnologia do Tocantins. OFíCIO CIRCULAR No 7/2020/REI/IFTO, Oferta de curso de Formação Continuada. Palmas, 29 de maio de 2020. [Documento impresso].

DA SILVA BARBOSA, E. O ESPAÇO DA FAVELA E SEUS IMPACTOS NO COMBATE À COVID19: uma discussão à luz de textos literários. Revista Observatório , v. 6, n. 3, p. a12pt, 1 maio 2020.

FREIRE, P. Educação e Mudança. Rio de Janeiro: Paz e Terra, 1979.

GASQUE, N. DE L.; DIAS, F. A.; RODRIGUES, F. G.; MARVULLI, M. V. N.; MORAES, N. R. DE. COVID-19 AND THE GREAT PANDEMICS OF HUMANITY: a historical and sociological view. Revista Observatório , v. 6, n. 3, p. a17en, 1 maio 2020.

GRILLI, M. DECOLONIZAR O PRECARIADO EM MEIO À PANDEMIA: Covid-19 versus Ciências Humanas. Revista Observatório, v. 6, n. 3, p. a6pt, 1 maio 2020. 


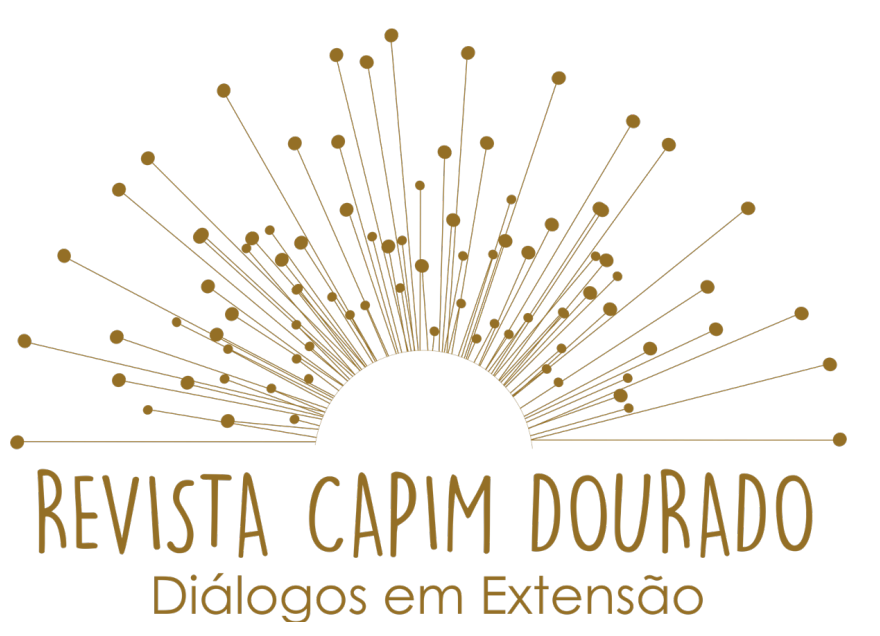

ISSN n² 2595-7341

Vol. 3, n. 2, Maio-Agosto, 2020

DOI: http://dx.doi.org/10.20873/uft.2595-7341.2020v3n2p30

IESA, UFG. Simpósio-Ciência, Arte e Educação em tempos de pandemia. Disponível em: $<$ https://iesa.ufg.br/n/128742-simposio-ciencia-arte-e-educacao-em-tempos-depandemia>. Acesso em 27 jun. 2020.

NEPPEC, $F E$, UFG. Diálogos em tempos de cólera. Disponível em: <https://neppec.fe.ufg.br/n/127272-programacao>. Acesso em 27 jun. 2020.

OLIVEIRA, Hudson do Vale de. SOUZA, Francimeire Sales de. Do conteúdo programático ao sistema de avaliação: Reflexões educacionais em tempos de pandemia (COVID-19). Boletim de Conjuntura (BOCA) ano II, vol. 2, n. 5, Boa Vista, 2020.

PÔRTO JÚNIOR, F. G. R.; SANTOS, L. V. DOS; PEREIRA SILVA, M. DAS G. A PANDEMIA DA COVID-19: Os impactos e tendências nos processos de ensino, aprendizagem e formação continuada de professores. Revista Observatório , v. 6, n. 2, p. a8pt, 1 abr. 2020.

PORTO JUNIOR, F. G. R.; SANTOS, L. V. DOS; SILVA, M. DAS G. P. THE PANDEMIC OF COVID-19: The impacts and trends in the process of continuing teacher education. Revista Observatório, v. 6, n. 2, p. a8en, 1 abr. 2020.

PORTO JUNIOR, F. G. R.; SILVA, M. L. A. DA; SILVA, M. DAS G. P.; OLIVEIRA, R. P. DE. INTERFACES DA COVID-19 NA EDUCAÇÃO: ELEMENTOS E APONTAMENTOS INICIAIS NO TOCANTINS. Revista Observatório , v. 6, n. 2, p. al1pt, 1 abr. 2020.

PUC, DE MINAS. XIII Semana de Pedagogia: Pedagogia e Pedagog@s em Tempos de Pandemia. Disponível em: https://www.pucminas.br/salaimprensa/eventos/Paginas/XIII-Semana-de-Pedagogia-tempos-da-pandemia.aspx.

Acesso em 27 jun. 2020.

QUEIROZ, T. Z. P. de. Tecnologias de groupware para a educação: aprendizagem colaborativa semipresencial na universidade. Teresinha Zélia Pinto de Queiroz - 2003.

REBOUÇAS PÔRTO JUNIOR, F. G.; ANDRADE DA SILVA, M. L.; PEREIRA SILVA, M. DAS G.; PEREIRA DE OLIVEIRA, R. COVID-19 INTERFACES IN EDUCATION: INITIAL ELEMENTS AND NOTES IN TOCANTINS. Revista Observatório , v. 6, n. 2, p. a11en, 1 abr. 2020.

RODRIGUES; A.L. L; PRATA, M. S; BATALHA, T. B. S; COSTA, C. L. N. do A; NETO, I. de F. P. contribuições da extensão universitária na sociedade. Cadernos de Graduação - Ciências Humanas e Sociais. Aracaju, v. 1, n.16 p. 141-148, mar. 2013.

ROSENAU, L. DOS S.; DYCK, M. S.; PEGORINI, D. G.; URBANETZ, S. T. WOULD DISTANCE EDUCATION BE THE ANSWER FOR A PANDEMIC TIME?. Revista Observatório, v. 6, n. 3, p. a15en, 1 maio 2020.

ROSENAU, L. DOS S.; SIMONIAN DŸCK, M.; GURGEL PEGORINI, D.; URBANETZ, S. T. SERIA A EDUCAÇÃO A DISTÂNCIA A RESPOSTA PARA UMA ÉPOCA DE PANDEMIA?. Revista Observatório, v. 6, n. 3, p. a15pt, 1 maio 2020. 


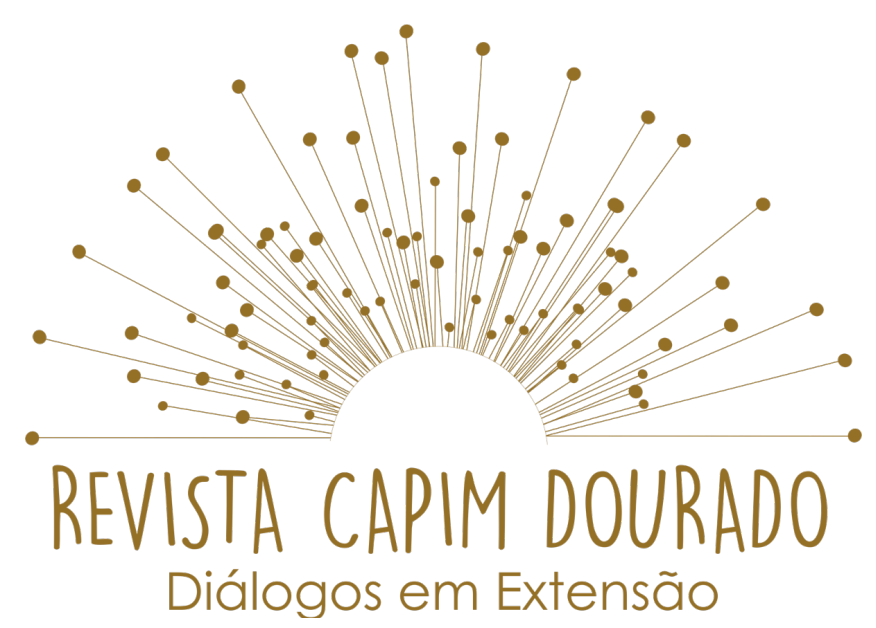

ISSN n² 2595-7341

Vol. 3, n. 2, Maio-Agosto, 2020

DOI: http://dx.doi.org/10.20873/uft.2595-7341.2020v3n2p30

SAM, Semana de Ação Mundial. Manual SAM 2020. Disponível em: <https://semanadeacaomundial.org/2020/>. Acesso em 27 jun 2020. [Documento impresso, 56 p].

SANTOS, B. de S. A Cruel Pedagogia do Vírus. Edições Almedina, ISBN 978-972-40-84961 - CDU 347 - 2020.

SILVA, V. Ensino, pesquisa e extensão: Uma análise das atividades desenvolvidas no GPAM e suas contribuições para a formação acadêmica. In: XX Congresso Nacional da Associação Brasileira de Educação Musical: Educação Musical para o Brasil do Século XXI. 2011, Vitória, Revista ABEM. Vitória, novembro de 2011.

SOARES, Sávia Bona V. Coronavírus e a modernização conservadora da educação. In: SOARES et al. Coronavírus, educação e luta de classes no Brasil. Editora Terra Sem Amos: Brasil, 2020. material digital, $45 \mathrm{p}$.

SOUSA, F. DA C.; MORAES, N. R. DE; QUIQUETO, A. M.; TEODORO, V. B. COVID-19 E POVOS INDÍGENAS: Aspectos de seguridade social. Revista Observatório, v. 6, n. 2, p. a12pt, 1 abr. 2020.

SOUZA, F. DA C.; MORAES, N. R. DE; QUIQUETO , A. M.; TEODORO, V. B. COVID-19 AND INDIGENOUS PEOPLES: Aspects of social security. Revista Observatório, v. 6, n. 2, p. a12en, 1 abr. 2020.

SOUZA, Â. R. de; TAVARES, T. M. GESTÃO DEMOCRÁTICA DA ESCOLA E DA EDUCAÇÃO: da teoria à prática. In. AZEVEDO, J. M. L. de, AGUIAR, M. A. da S. Qualidade Social da Educação Básica. (Organizadores) - Camaragibe. PE: CCS Gráfica e Editora, 2016. Coletânea, 152 páginas. ISBN: 978-85-60917-52-5.

UFT, Universidade Federal do Tocantins. UFT inicia semana de reuniões online para discussão de novas práticas pedagógicas. Disponível em: <https://ww2.uft.edu.br/index.php/ultimas-noticias/27557-uft-inicia-semana-dereunioes-online-para-discussao-de-novas-praticas-pedagogicas $>$. Acesso em 28 jun 2020. 